\title{
How Much Sciatic Nerve Does Hip Flexion Require?
}

\author{
Lawrence R. Robinson (10, Linda Probyn
}

\begin{abstract}
Measured nerve conduction velocity in the fibular nerve increases across the knee during hip flexion. This is due to stretching of sciatic and fibular nerves. We modeled the additional nerve length required for the sciatic nerve to course around the flexed hip, based upon distance between the hip and the sciatic nerve on magnetic resonance imaging (MRI). The median distance from the femoral head to the sciatic nerve was $41 \mathrm{~mm}$. The model predicted that $64 \mathrm{~mm}$ of sciatic nerve is required for hip flexion. This impacts our understanding of lower limb nerve conduction studies and clinical straight leg raising tests.

RÉSUMÉ: Quelle est la longueur de nerf sciatique nécessaire pour une flexion des hanches? Pour l'avoir mesurée, on sait que la vitesse de conduction nerveuse dans le nerf fibulaire augmente à travers le genou au moment d'une flexion des hanches. Cela s'explique par l'élongation des nerfs sciatique et fibulaire. Pour créer un modèle rendant compte de la longueur additionnelle dont a besoin le nerf sciatique pour contourner une hanche fléchie, nous nous sommes basés sur la distance entre une hanche et le nerf sciatique lors d'une IRM. Ainsi, la distance médiane entre la tête fémorale et le nerf sciatique était de $41 \mathrm{~mm}$. Notre modèle avait plutôt prédit qu'un nerf sciatique long de $64 \mathrm{~mm}$ était nécessaire pour une flexion des hanches. Cela devrait avoir une incidence sur notre compréhension des études portant sur la conduction nerveuse des membres inférieurs et des tests cliniques dans lesquels on demande aux patients de lever leur jambe vers le haut.
\end{abstract}

Keywords: Sciatic nerve, Nerve length

doi:10.1017/cjn.2018.378

Can J Neurol Sci. 2019; 46: 248-250

In a prior report ${ }^{1}$, measured nerve conduction velocity (NCV) in the fibular nerve across the knee was, on average, $2.6 \mathrm{M} / \mathrm{s}$ faster when subjects' hips were in flexion rather than extension, while the knee was fully extended. The increase in measured $\mathrm{NCV}$ is not due to faster physiologic conduction. Rather, it may be due to straightening of the sciatic and fibular nerves. When the hip is flexed, the nerve is fully stretched, and the length of nerve between stimulation sites is minimized. In this position, the surface distance between stimulation sites approximates the nerve distance. But, when the hip is extended, there is more nerve length than is needed to traverse a straight line between stimulation sites. As a consequence, in hip extension, there is more nerve length between the two stimulation sites, and surface measurements underestimate the true nerve length. The measured NCV (=surface distance/time) is greater with hip flexion because the time required to traverse the shorter segment of nerve is less.

Since the average conduction velocity over the knee segment increased from 49.7 to $52.3 \mathrm{M} / \mathrm{s}$ in the $90-\mathrm{mm}$ segment reported previously, ${ }^{1}$ it can be calculated that the length of nerve over which the signal traversed at the knee was reduced by about $5 \mathrm{~mm}$ with hip flexion.

This has led to the question of how much nerve length is required to course around the hip during hip flexion. The goal of this study is to model the extra length of sciatic nerve required to achieve $90^{\circ}$ hip flexion using imaging data, which will help inform the understanding of nerve conduction changes distally in the leg.

The model used for this study is shown in Figure 1. We assumed that the additional sciatic nerve length required to accommodate $90^{\circ}$ of hip flexion is represented by the segment "B." In this model, a circle with a radius of " $r$ " would have a circumference equal to $2 \pi r$. Since " $B$ " is only one-fourth of the circumference, we assumed that the length of the arc represented by segment $B$ would be one-fourth of the full circumference or $\pi r / 2$. If the distance between the center of rotation of the hip and the sciatic nerve $(r)$ could be measured, then the length of segment B could be estimated.

The distance between the center of the femoral head and the sciatic nerve was measured on retrospective review of MRI images of the pelvis by one of the co-authors (LP), who is an experienced musculoskeletal radiologist. Images were obtained from adults who already had imaging for other reasons. A circle was drawn at the level of the femoral head, and the center point of the femoral head was marked. The distance from the center of the femoral head to the sciatic nerve $(r)$ was obtained by drawing a line from the center of the femoral head to the sciatic nerve. This was performed for both hips on each image (Figure 2). Distances were recorded, along with age and gender. This study was approved by the Sunnybrook Health Sciences Centre Research Ethics Board.

The distance between the center of the femoral head and the center of the sciatic nerve was measured in 20 adults

From the Division of Physical Medicine and Rehabilitation, Sunnybrook Health Sciences Centre, University of Toronto, Toronto, Ontario, Canada (LRR); Department of Medical Imaging, Sunnybrook Health Sciences Centre, University of Toronto, Toronto, Ontario, Canada (LP)

Received July 16, 2018. Final Revisions Submitted September 29, 2018. Date of Acceptance OCtOBer 31, 2018.

Correspondence to: Larry Robinson, St. John's Rehab, S125 285 Cummer Ave., Toronto, Ontario M2M 2G1, Canada. Email: Larry.Robinson@Sunnybrook.ca 

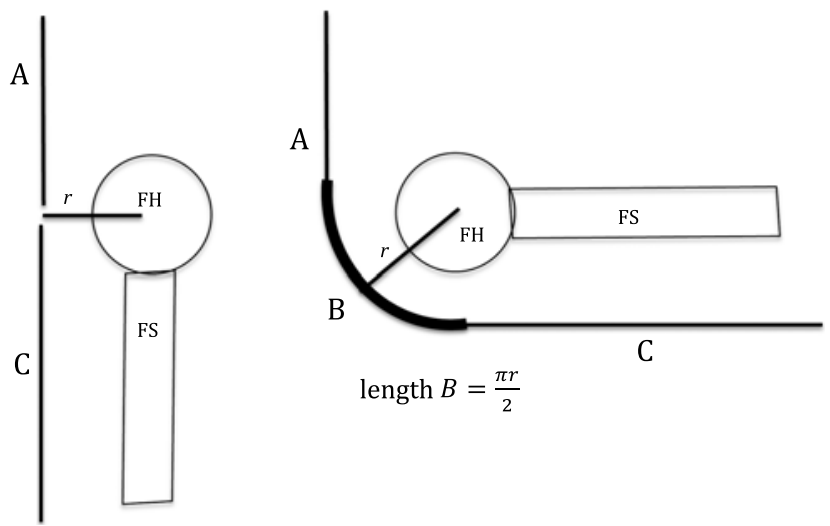

Figure 1: Sciatic nerve with hip extension (left) and hip flexion (right). $A=$ segment of sciatic nerve above center of femoral head. $C=$ segment of sciatic nerve below center of femoral head. $B=$ segment of sciatic nerve needed to accommodate hip flexion. $r=$ distance between center of femoral head and sciatic nerve. FH=femoral head. FS=femoral shaft.

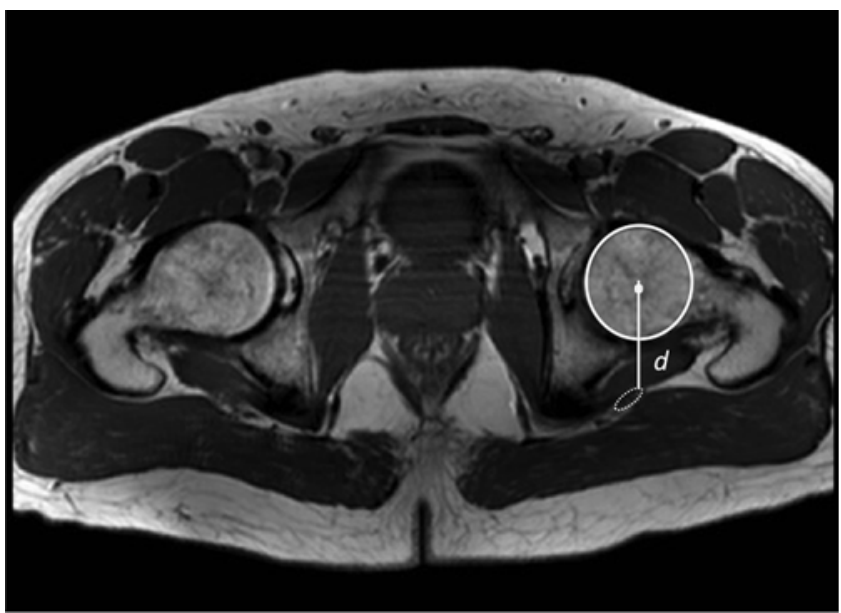

Figure 2: Axial T1 weighted MR image of both hips. A circle was drawn at the level of the femoral head, and the distance to the sciatic nerve was measured from the center of the femoral head by drawing a line posteriorly to the front margin of the sciatic nerve. This was performed for both hips.

(11 women and 9 men). The median distance was $41.0 \mathrm{~mm}$ (interquartile range $=38.0-45.9 \mathrm{~mm}$ ) (Table 1). Distances in men (mean $=44.1 \mathrm{~mm})$ were significantly greater than in women $($ mean $=39.9 \mathrm{~mm})(p<0.04)$ on both sides. Left and right distances were highly correlated with each other $(r=0.97$, $p<0.001$ ), but there was no correlation with age in this group of adults. Using the distance above, to approximate the length of segment B in Figure 2,

$$
B=\frac{\pi r}{2}
$$

one obtains a median length of $64 \mathrm{~mm}$ (interquartile $=$ range 60-73 mm). This is the predicted length of nerve required to accommodate hip flexion.

It is clear that joint position affects the course of nerves traversing that joint, which is manifested as changes in NCV with joint position changes. The most marked reported effects are for the ulnar nerve with elbow flexion ${ }^{2}$ and the fibular nerve with
Table 1: Distance between center of femur and sciatic nerve (mm)

\begin{tabular}{l|c|c}
\hline & Right & Left \\
\hline Mean \pm sd & $41.8 \pm 4.3$ & $41.8 \pm 4.4$ \\
\hline Median & 41.4 & 41.0 \\
\hline Range & $34.4-48.9$ & $34.4-48.9$ \\
\hline Men & $44.0 \pm 3.5$ & $44.1 \pm 3.7$ \\
\hline Women & $40.0 \pm 4.2$ & $39.8 \pm 4.1$ \\
\hline
\end{tabular}

hip flexion. ${ }^{1}$ When nerves wrap around the extensor side of a flexed joint, whether the elbow or the hip, they need to be able to accommodate the added distance to wrap around the joint as well as the tissue intervening between the joint and the nerve. As modeled in Figure 1, the greater the distance between the center of joint rotation and the nerve $(r)$, the greater the length of nerve required.

This understanding has created a commonly accepted practice of keeping the elbow in flexion during measurements of NCV. While not yet standard, we believe the practice of keeping the hip in flexion and knee in extension during lower limb NCV measurements should be similarly adopted. We have only studied and modeled $90^{\circ}$ hip flexion but do not know if a lesser amount of flexion would be sufficient.

This study examines the estimate of how much sciatic nerve is required to accommodate hip flexion. We estimate that, on average, an additional $64 \mathrm{~mm}$ is required to wrap around a flexed hip joint. Given that approximately $5 \mathrm{~mm}$ of nerve length is taken out of the segment between popliteal fossa and fibular head, one can estimate that about $8 \%$ of the length required from hip flexion is derived from that more distal segment. Presumably, the remainder of the required length comes from other segments of the nerve, both proximally and distally. It would be of interest to measure whether tibial nerve conduction velocity in the leg segment is also affected by hip position, but this has not yet been studied.

This model may also help with an understanding of the commonly performed straight leg raising test as well. ${ }^{3}$ As the hip is elevated into flexion, with the knee in extension, the pull on the sciatic nerve and attached nerve roots reproduces pain from stretching of already inflamed nerve roots. From our model, we estimate that over $6 \mathrm{~cm}$ of nerve length is required to accommodate hip flexion to $90^{\circ}$, which likely translates to significant stretch of the nerve root at the neural foramen.

The model used in this study to estimate the radius of the curve "B" in Figure 1 has limitations. First, the nerve may not follow a curved path with uniform distance from femur to sciatic nerve as in the model, in which case the length of nerve required may not be as long as that modeled. Moreover, since MRIs were performed in the supine position, we don't know if the sciatic nerve moves closer to the femur during hip flexion. Presumably, however, soft tissues were already compressed by having the patient supine during imaging.

\section{ACKNOWLedgements}

The authors acknowledge the John and Sally Eaton Chair in Rehabilitation Science at Sunnybrook Health Sciences Centre. 


\section{STATEMENT OF AUTHORSHIP}

Dr. Probyn performed measurements on images and collaborated on development of the mathematical model. Dr. Robinson analyzed the data and led development of the mathematical model.

\section{Disclosures}

LRR and LP have nothing to disclose.

\section{REFERENCES}

1. Broadhurst PK, Robinson LR. Effect of hip and knee position on nerve conduction in the common fibular nerve. Muscle Nerve. 2017;56:519-21.

2. Checkles NS, Russakov AD, Piero DL. Ulnar nerve conduction velocity - effect of elbow position on measurement. Arch Phys Med Rehabil. 1971;52:362-5.

3. Deville WL, van der Windt DA, Dzaferagic A, Bezemer PD, Bouter LM. The test of Lasegue: systematic review of the accuracy in diagnosing herniated discs. Spine. 2000;25:1140-7. 